\title{
LOCAL MANUFACTURING ESTABLISHMENTS AND THE EARNINGS OF \\ MANUFACTURING WORKERS: \\ INSIGHTS FROM MATCHED EMPLOYER-EMPLOYEE DATA
}

\author{
by \\ Charles M. Tolbert * \\ Baylor University \\ and \\ Troy C. Blanchard * \\ Louisiana State University
}

CES 11-01 January, 2011

The research program of the Center for Economic Studies (CES) produces a wide range of economic analyses to improve the statistical programs of the U.S. Census Bureau. Many of these analyses take the form of CES research papers. The papers have not undergone the review accorded Census Bureau publications and no endorsement should be inferred. Any opinions and conclusions expressed herein are those of the author(s) and do not necessarily represent the views of the U.S. Census Bureau. All results have been reviewed to ensure that no confidential information is disclosed. Republication in whole or part must be cleared with the authors.

To obtain information about the series, see www.census.gov/ces or contact Cheryl Grim, Editor, Discussion Papers, U.S. Census Bureau, Center for Economic Studies 2K130B, 4600 Silver Hill Road, Washington, DC 20233, CES.Papers.List@census.gov. 


\begin{abstract}
We analyze the earnings determination process of more than 400,000 rural manufacturing workers in 12 selected U.S. states. Our theoretical motivation stems from an ongoing interest in the benefits of locally oriented business establishments. In this case, we distinguish manufacturing concerns that are single establishments in one rural place from branch plants that are part of larger multi-establishment enterprises. Our data permit us to introduce attributes of both workers and their employing firms into earnings determination models. For manufacturing workers in "micropolitan" rural counties, we find that working for a local (single) establishment has a positive impact on annual earnings. However, tenure with a firm returns more earnings for workers in non-local manufacturing facilities. Conversely, for manufacturing workers in "noncore" or rural areas without urban cores, we find that working for a local establishment has a negative effect on earnings. But, job tenure pays off more when working for a local establishment.
\end{abstract}

* This analysis was conducted at the Chicago Census Research Data Center where the authors hold Special Sworn Status. Any opinions and conclusions expressed herein are those of the authors and do not necessarily represent the views of the U.S. Census Bureau. All results have been reviewed to ensure that no confidential information is disclosed. A portion of this research was funded by USDA-NRI Grant.No. LAR-2008-02151 and NSF Grant No. 0757201. This research uses data from the Census Bureau's Longitudinal Employer Household Dynamics Program, which was partially supported by the following National Science Foundation Grants SES-9978093, SES-0339191 and ITR0427889; National Institute on Aging Grant AG018854; and grants from the Alfred P. Sloan Foundation. 


\section{Introduction}

For more than a decade, researchers in the civic community, local capitalism, and related traditions have studied the implications of locally oriented business establishments for rural communities. Defining "local" in a variety of ways, researchers have found that communities with proportionately more local business establishments have higher income levels, less poverty, less unemployment, and less crime. But, these community-level studies cannot specify the underlying mechanisms by which these beneficial outcomes come to pass. How is it, for example, that incomes are higher in a community with mostly locally oriented manufacturing establishments as opposed to mostly branch plants controlled by distant corporations? Addressing this question requires a link between the macro- and micro-levels-i.e., information about the rural community, its manufacturing establishments, and the employees of those establishments. And, for representativeness and state and national policy relevance, that information would also need to be broad in geographic coverage yet sufficiently detailed to permit the identification of rural communities. Until very recently, there were no such data.

We have two aims in this paper: 1) conduct a macro-micro assessment of some of the key tenets of the civic community in rural areas, and 2 ) introduce a very promising new data resource to the rural social science community. The first objective is addressed by revisiting some of the earliest and most consistent findings in the civic community literature: the positive impact of locally oriented manufacturing establishments. To accomplish the second objective, we employ a promising new data resource that matches workers and employers: the Longitudinal Employer-Household Dynamics database (LEHD). From this massive database, we extract 450,000 rural manufacturing workers and employers from 12 selected states circa 2000. We estimate a conventional earnings determination model. The analysis includes attributes of manufacturing establishments such as single location versus branch plant, number of employees, and length of presence in the community. For employees, the models include basic demographic and human capital information plus a measure of tenure with the employer and an indicator of multiple job-holding. The findings shed light on the mechanisms underlying the frequently observed, beneficial consequences of civic community and local capitalism.

\section{Review of Civic Community Research Tradition}

In a number of papers and books, we have elaborated on what we mean by civic community. ${ }^{1}$ The perspective focuses on social and economic structures and institutions that buffer communities from external, usually global, forces. This leads us to identify and study important community organizations such as locally oriented business establishments, civic organizations, associations, and churches. These critical entities, in turn, are posited to benefit communities through an enhanced quality of life, more civic engagement by the citizenry, and a strong capacity for local problem solving. Locally oriented businesses have stakes in the local labor market, the local economy, the local infrastructure, and - usually - the local product market. As the community goes, so go these entities. Persons owning, managing, and working in these establishments rarely employ a multinational or corporate perspective. The worldview is local. To lay off workers in slack times, for example, would mean taking jobs from relatives, friends, and neighbors. In Abbeville, one service station owner was

\footnotetext{
${ }^{1}$ For an overview of this line of work, see Irwin et al. (2004); Lyson (2004); Lyson and Tolbert (2003); Tolbert, Lyson, and Irwin (1998); Tolbert et al. (2001); Tolbert (2005).
} 
extremely proud that - at the height of the oil bust - he had employed 10 relatives to pump gas. To this day, folks drive into town and pay more at his station than they would at the self-service quick stops along the bypass. Let me describe further how we have defined the notion of locally oriented businesses.

Our earliest efforts (Irwin, Tolbert, and Lyson 1999; Lyson and Tolbert 1996; Tolbert, Lyson, and Irwin 1998) focused on small manufacturing establishments. What we observed in thriving rural areas were clusters of small production facilities almost always nested in cooperative networks. Economists refer to agglomerations of these as industrial districts. In addition to small manufacturing establishments, we have more recently studied locally oriented enterprises primarily in retail and services (Irwin et al. 2004; Tolbert et al. 2002). We classify single business establishments as locally oriented. The entire enterprise exists in one location. These local distinctions cannot be made with public-domain data. Instead, we have developed measures using confidential Economic Census microdata. These establishment-level data are housed at Census (in its Center for Economic Studies) and at its affiliated Research Data Centers around the country.

In this paper, we return to the subject of some of our original findings: manufacturing. In particular, we want to explore how the benefits of civic community work in the employer-employee relationship. What we have observed in the aggregate seems very promising, yet we know little about how it is that community features get translated into individual residents' lives and fortunes.

\section{Why Manufacturing Matters}

Researchers have shown much interest in rural manufacturing over the years, and that interest is clearly warranted. As agricultural employment dwindled across the $20^{\text {th }}$ century, manufacturing employment became vital for many rural communities. In a brief written for the White House, Deavers (1979:108) chronicled the increasing industrial diversity of rural employment in the 1970s: "An economic development policy intended to address the needs of the entire rural and small-town population will not succeed today if focused primarily on farming and agribusiness." Lloyd (1985:88) flatly states that manufacturing is "... the leading source of jobs in nonmetropolitan America."

Though manufacturing employment has since seen a secular decline across the board, those earlier observations about its significance for nonmetropolitan areas from the 1970s and 1980s largely still hold today. If anything, manufacturing employment is now actually more important for rural America than it is for the metropolitan U.S. Data for 2006 from the Bureau of Economic Analysis industry employment estimates series shows the continued importance of rural manufacturing (see Figures 1 and 2). Using the 2003 metropolitan area classification system (Office of Management and Budget, 2000), the BLS manufacturing employment data for 2006 indicate that 9 percent of metropolitan employment was in manufacturing, 12 percent in micropolitan counties, and 8 percent in "non-core" nonmetropolitan counties that have no urban core area. These manufacturing employment percentages are down from the 1969 figures of 20 percent (metropolitan), 19 percent (micropolitan), and 12 percent (non-core). While the effects of industrial restructuring are apparent in these numbers, it is important to note that the proportional employment decline in rural counties has not been as large as in metropolitan counties. The same BEA data also report on sources of earnings in counties. In 2006, manufacturing earnings accounted for 18 percent of all earnings in micropolitan counties (down from 24 percent in 1969). The parallel figures for non-core, nonmetropolitan counties are 12 percent of 2006 earnings due 
to manufacturing versus 14 percent in 1969. Restructuring notwithstanding, manufacturing continues be a non-trivial source of income for workers in rural American counties.

\section{Research Design for Studying Earnings Determination in Rural Manufacturing}

Our civic community framework conceives of the earnings determination process as (at least) a twolevel process. At one level, we have individual workers and their skills and work experience. The workers are nested in employing business establishments that have their characteristics as well. Chief among those establishment factors in our view is the extent of local orientation. Is business primarily done within a single area or is the establishment part of some larger enterprise that may be located in many communities.

To study earnings determination among rural manufacturing workers, then, we would ideally have data on workers and on the establishments in which they are employed. But, assembling such information has proven elusive in most cases. This is not a new problem. For want of better data, the wheels have been spinning for nearly 30 years in the American approach to social stratification and earnings analysis. Labor economists admit much the same for their domain (Abowd, Haltiwanger, and Lane, 2004). Good studies suffer for some combination of the following reasons: insufficient data on workers, insufficient data on organizations, and/or data collected at a single point in time. Until very recently, alternatives have not been available. The Longitudinal Employer-Household Database at Census, however, has the potential to jumpstart stratification work. We provide an overview in the section that follows.

\section{Overview of LEHD}

To address data issues noted above, analysts can now employ data from a large-scale, NSF-supported data program that provides a comprehensive longitudinal employer-employee database on U.S. workers and employers. Access to the data can only be had in secure lab settings known as Census Research Data Centers (RDCs). The vast database draws on a variety of government data and administrative records on businesses and on household surveys, permitting approved users to link information on businesses with data on employees. The Longitudinal Employer-Household Dynamics (LEHD) program at the U.S. Census Bureau is a linked employer-employee data file that provides quarterly labor market information for the vast majority of labor force participants in most states (Abowd, et al. 2005). At present, 47 states participate in the LEHD program with a goal of full U.S. coverage. ${ }^{2}$ LEHD data are well suited to the study of mobility and earnings because the data contain information on the worker and the worker's employing organization. In addition, information on all establishments that have operated in a state during a given period of time is available. These data on the organizational population are useful for the construction of organizational environment measures such as the organizational dissolution rate or the rate of job creation due to organizational foundings or expansions.

Linked employee-employer data are created from Unemployment Insurance (UI) wage record data for employees and ES202 establishment summary wage data for employers. These data come from UI filings by each establishment operating in a given state. The UI program was instituted in 1935 as a part

\footnotetext{
${ }^{2}$ An up-to-date list of participating states and further information can be found on the LEHD web site at http://lehd.did.census.gov/led/ .
} 
of the Social Security Act and is currently administered by each state. Most employers are required by law to pay unemployment insurance on a quarterly basis. In doing so, employers submit listing of personnel and wage information for each worker. UI and ES202 data contain information on the majority of private sector, nonagricultural employers and employees. Excluded are federal employees, agricultural workers, domestic workers, the self-employed, members of the Armed Services, state and local government workers, and some employees of nonprofit employers and religious organizations. These employees are excluded because their employing establishments do not participate in the Unemployment Insurance program.

At the employee level, UI data are collected quarterly in all U.S. states and capture $98 \%$ of all employment (Andersson et al. 2002). Quarterly UI records contain information on the employee's wages, work establishment identifier, and Social Security Number. With the Social Security Number converted to a Census PIK (Person Identifier Key), these data comprise the foundation of the employeelevel file. To create a longitudinal employee-level file, the U.S. Census Bureau links quarterly UI observations for each individual appearing in the UI database. In this longitudinal format, it becomes possible to measure tenure of the worker at a particular establishment, multiple job-holding, and to follow the worker through a series of jobs that may constitute a work career. The current LEHD database contains all workers appearing in UI records from 1990-2004 (coverage through 2008 is expected shortly).

Employer-level data are based on the ES202 quarterly employment and tax reports submitted by all employers subject to Unemployment Insurance legislation. ES202 data contain a work establishment identifier and establishment-level information on the number of employees, total wages, whether or not the establishment is part of a single- or multi- establishment firm, and industry classification. Employerlevel information during a given quarter is attached to employee information using the work establishment identification code.

A unique aspect of LEHD data is the capacity to link information from a variety of administrative and Census program data to enhance the limited information provided in the UI data files. At the worker level, information linked from the Current Population Survey series, Decennial Census, Survey of Income and Program Participation, and Social Security Administration records is used to obtain data not collected in the UI program. This is key social and demographic information such as age, race, sex, place of birth (including foreign born status), place of residence and work (including latitude and longitude coordinates), and education. Similarly, business establishment ID codes can be used to attach information on the employer. Data available here include quarterly total employment and wages plus information on the longevity of the establishment.

Due to the sensitive and confidential nature of the information in the LEHD, there is no publicly available version (these data are protected under Titles 13 and 26 of the U.S. Code). Housed in the Census Bureau's Research Data Center (RDC) system, the LEHD can only be accessed on site at one of the RDCs. There are presently 10 RDCs around the country and several more are in various stages of proposal and development. ${ }^{3}$ Users of the data must have proposals approved by both the Census Bureau and the Internal Revenue Service (a few of the data items are considered Federal Tax Information-FTI). Users must also hold Special Sworn Status at the Census Bureau. While these regulations set a somewhat high

\footnotetext{
${ }^{3}$ For more information on the Census RDC system, see: www.census.gov/ces.
} 
barrier to entry, it is increasingly the case that social scientists are succeeding in using LEHD. Some of our first findings with these data are presented in the section that follows.

\section{Earnings of Rural Manufacturing Workers in LEHD}

We have noted above that using matched employer-employee data has the potential to address a number of lingering issues in recent American stratification research. Use of LEHD can improve on earlier work in a number of ways. These include far larger samples that can stand by themselves or be filtered to derive interesting research subsamples. Rather than inferring attributes of employers by proxies like industry codes, the researcher has exact details of the employing establishment (or firm). Information is available for an extended period of time, improving greatly on single cross-sectional survey designs. To ensure confidentiality, public-use data have very limited geography. In LEHD, precise place of residence and place of work is known to the point of geocodes. We show how these advantages can be leveraged in the analysis below.

In this civic community analysis, we are concerned with the extent to which manufacturing establishments are locally oriented. One indicator of local orientation is whether the entity is a single establishment (one location) or part of a larger, multi-establishment enterprise. We view the single establishment as far more likely to have a stake in the locality, the local workforce, and its own employees. Another indicator of local orientation is the longevity of the establishment in the community. This we see as a sign of embeddedness, and we posit that longer durations will result in more favorable outcomes for rural workers and their communities. These indicators of local orientation can be readily derived from existing information on employers in LEHD. We expect to observe that employees of locally oriented establishments will fare somewhat differently from employees of nonlocal establishments and firms.

As rural sociologists, we require data that permit us to use the standard definitions of urban and rural implied by the Federal metropolitan classification system (Office of Management and Budget, 2000). That system classifies counties as parts of metropolitan areas (must have 50,000-person core area) or micropolitan areas (core populations of 10,000-49,999). That leaves about 700 U.S. counties in a nonmetropolitan residual group we refer to as non-core areas. Using this classification of counties, we focus our analysis on rural areas that are either micropolitan or non-core. It is important to note that public-use survey data typically do not identify rural counties because of small populations and confidentiality concerns. LEHD has county identifiers on all employer records, so we are able to classify places of work as metropolitan, micropolitan, or non-core.

Analysis Strategy. We estimate models that predict rural manufacturing workers' earnings in the year 2000. Each LEHD state-level data file contains millions of records. To keep things manageable, we are conducting our analysis on 12 states that are fairly representative of U.S. regions and known for substantial agricultural activity (see Figure 3). From the full database, we extract manufacturing workers who had positive earnings in all four quarters of 2000. The overall period of observation is 1992-2000. This results in about 250,000 micropolitan manufacturing workers and 205,000 non-core manufacturing workers. 
The models are estimated separately for the two populations of workers. One set of predictors in the models are individual-level attributes generally available in household survey data and long known to affect earnings:

- Experience (age-based), experience squared

- Female, Hispanic, African American, Other race

- Years of schooling

Another set of variables is work-career related and could only be derived with longitudinal data such as LEHD:

- Multiple job holding: Number of 4-quarter jobs held in 2000

- Tenure: Number of consecutive quarters with establishment

LEHD also permits us to include information on the employing establishment or firm:

- Embeddedness: Consecutive quarters in community

- Size: LN of number of employees

- Single establishment (local orientation)

Since LEHD is assembled state by state, there can be variations in the data due to differential state policies on data collection and release to Census. Of course, states also vary in many other ways that might influence an earnings analysis (e.g., prevailing wage rates, education levels). Thus, we enter a set of 11 state binary variables into our models, omitting Maryland as a contrast. The regression results we discuss below are net of these state indicators.

Results. Table 1 shows descriptive statistics for rural manufacturing workers by our rural geographies (micropolitan counties and non-core counties). Not surprisingly, earnings for the most rural of workersthe non-core workers-are slightly lower than for micropolitan workers. Years of work experience are about equal as are gender distributions across the rural area types. Very small differences are evident in race and ethnicity. Micropolitan manufacturing workers exhibit two-tenths of a year more schooling. Micropolitan workers have been with their employing firms for almost two quarters longer than their non-core counterparts.

In terms of characteristics of employers, the establishments show about the same length of time in the communities. Neither type of area can claim more embeddedness of manufacturing firms as measured by longevity in the locality. Manufacturing plants in micropolitan and non-core areas are about the same size. And, lastly, there is a slightly higher proportion of single manufacturing establishments in non-core areas than in micropolitan areas.

Table 2 contains basic earnings models for both area types in columns 1 and 3 . The large volume of data virtually ensures statistical significance of the coefficients. The models are very similar. As the standardized coefficients indicate, in both micropolitan and non-core rural areas, the best predictors of manufacturing workers' earnings are experience, gender, establishment size, and tenure with the firm. Note that a characteristic of the employer out-performs any number of individual workers attributes in these models of the earnings determination process. The civic community indicators duration in the community and locally oriented (single) establishment show negative direct effects on earnings. Models 
2 and 4 show some of our other findings related to the civic variables when expressed in interaction terms. There we see an intriguing difference between micropolitan and non-core rural areas on the interaction between single establishment and tenure with the firm. In micropolitan areas, working for a single manufacturing establishment reduces the benefit of tenure with firm. In non-core rural areas, employment with a locally oriented (single) establishment increases the earnings returns to time with the employer. And, the standardized coefficients suggest that these are important effects in the models relative other included predictors. In fact, tenure with the firm is not very important in non-core areas until we add the interaction for single establishment.

Summary of Findings. To be sure, we find little difference across the two types of rural areas. The processes that generate annual earnings of workers in micropolitan and non-core rural areas are much the same. There are interesting contrasts with metropolitan earnings processes, but we will not go into those in this paper. We find that the individual-level variables behave as expected in our models. Experience and schooling are associated with higher earnings for rural manufacturing workers. Being female, Hispanic, or black has a negative effect on earnings. The work-career variables show that holding other jobs actually dampens earnings at the primary manufacturing job. And, tenure with the establishment has a strong, positive effect on earnings. Among the firm attributes, establishment size has a positive effect. That is, the larger the manufacturing establishment, the higher the earnings of the workers. Both of our local orientation variables have negative effects on earnings per se. However, in our more detailed analyses, we have found some interesting statistical interactions which sharpen our understanding of how local orientation affects manufacturing earnings. Specifically, we find an interaction between tenure on the job and single establishment. This suggests that the influence of local orientation works through differences in key variables such as tenure on the job. In the local establishment, longer job tenures are rewarded more so than in non-local establishments. This more nuanced conclusion is typical of that possible with a resource like LEHD.

\section{Conclusion}

We have a twofold objective in this paper: 1 ) conduct a macro-micro assessment of some of the key tenets of the civic community in rural areas, and 2 ) introduce a very promising new data resource to the rural social science community. We address the first objective by revisiting some of the earliest and most consistent findings in the civic community literature: the positive impact of locally oriented manufacturing establishments. What we find is that the influence of locally oriented manufacturing on manufacturing wages plays out in a complex way in rural areas. In most rural of areas-non-core nonmetropolitan counties-working tenure with the locally oriented, single manufacturing establish pays off substantially. But, the same does not hold for manufacturing workers in micropolitan areas or medium-size towns.

To accomplish the second objective, we employ a promising new data resource that matches workers and employers: the Longitudinal Employer-Household Dynamics database (LEHD). The confidential Census data contain very large numbers of workers and permit us to make rural areas distinctions like micropolitan and non-core. Moreover, the longitudinal character of the employer and employee data allows us to compute measures such as tenure of the worker with the firm and longevity of the business in the community. While this may be the first exploration of this massive data base by rural sociologists it will certainly not be the last. Such is the promise of this new data resource. 


\section{References}

Abowd, John M., John C. Haltiwanger, and Julia C. Lane. 2004. "Integrated Longitudinal EmployeeEmployer Data for the United States." U.S. Census Bureau, LEHD Program, Washington D.C.

Abowd, John M., Bryce E. Stephens, Lars Vilhuber, Frederick Andersson, Kevin L. McKinney, Marc Roemer, and Simon Woodcock. 2005. "The LEHD Infrastructure Files and the Creation of the Quality Workforce indicators." U.S. Census Bureau, LEHD Program, Washington D.C.

Andersson, Frederick, Harry J. Holzer, and Julia I. Lane. 2002. "The Interactions of Workers and Firms in the Low-Wage Labor Market." U.S. Census Bureau, LEHD Program, Washington D.C.

Irwin, Michael D. , Charles M. Tolbert, and Thomas A. Lyson. 1999. "There's No Place Like Home: NonMigration and Civic Engagement." Environment and Planning A 31: 2223-38.

Irwin, Michael, Troy Blanchard, Charles Tolbert, Thomas Lyson, and Alfred Nucci. 2004. "Why People Stay: The Impact of Community Context on Nonmigration in the USA." Population 59:567-592.

Lyson, Thomas A. 2004. Civic Agriculture: Reconnecting Farm, Food and Community. University Press of New England.

Lyson, Thomas A. and Charles M. Tolbert. 1996. 'Small manufacturing and nonmetropolitan socioeconomic well-being', Environment and Planning-A 28:1779-1794.

Office of Management and Budget. 2000. "Standards for Defining Metropolitan and Micropolitan Statistical Areas." Federal Register 65: 82227-82238.

Sharp, Jeff S. and J. L. Flora. 1999. "Entrepreneurial Social Infrastructure and Growth Machine Characteristics Associated with Industrial-Recruitment and Self-Development Strategies in Nonmetropolitan Communities." Journal of the CommunityDevelopment Society 30:131-153.

Tolbert, Charles M. 2005.. "Minding Our Own Business: Locally Oriented Business and the Future of Southern Civic Community." Social Forces 83:1309-1328.

Tolbert, Charles M., Lyson, Thomas A. and Irwin, Michael . 1998. 'Local capitalism, civic engagement, and socioeconomic welfare', Social Forces 77:401-427.

Tolbert, Charles M., Troy C. Blanchard, Michael D. Irwin, Thomas A. Lyson, and Alfred R. Nucci. 2001. "Engaging Business: Civic Engagement and Locally Oriented Firms." Southern Perspectives 5(Fall):1-4.

Tolbert, Charles M., Michael Irwin, Thomas Lyson, and Alfred Nucci. 2002. "Civic Community in SmallTown America." Rural Sociology 67:90-113. 
Figure 1. Manufacturing Employment by Metropolitan Status

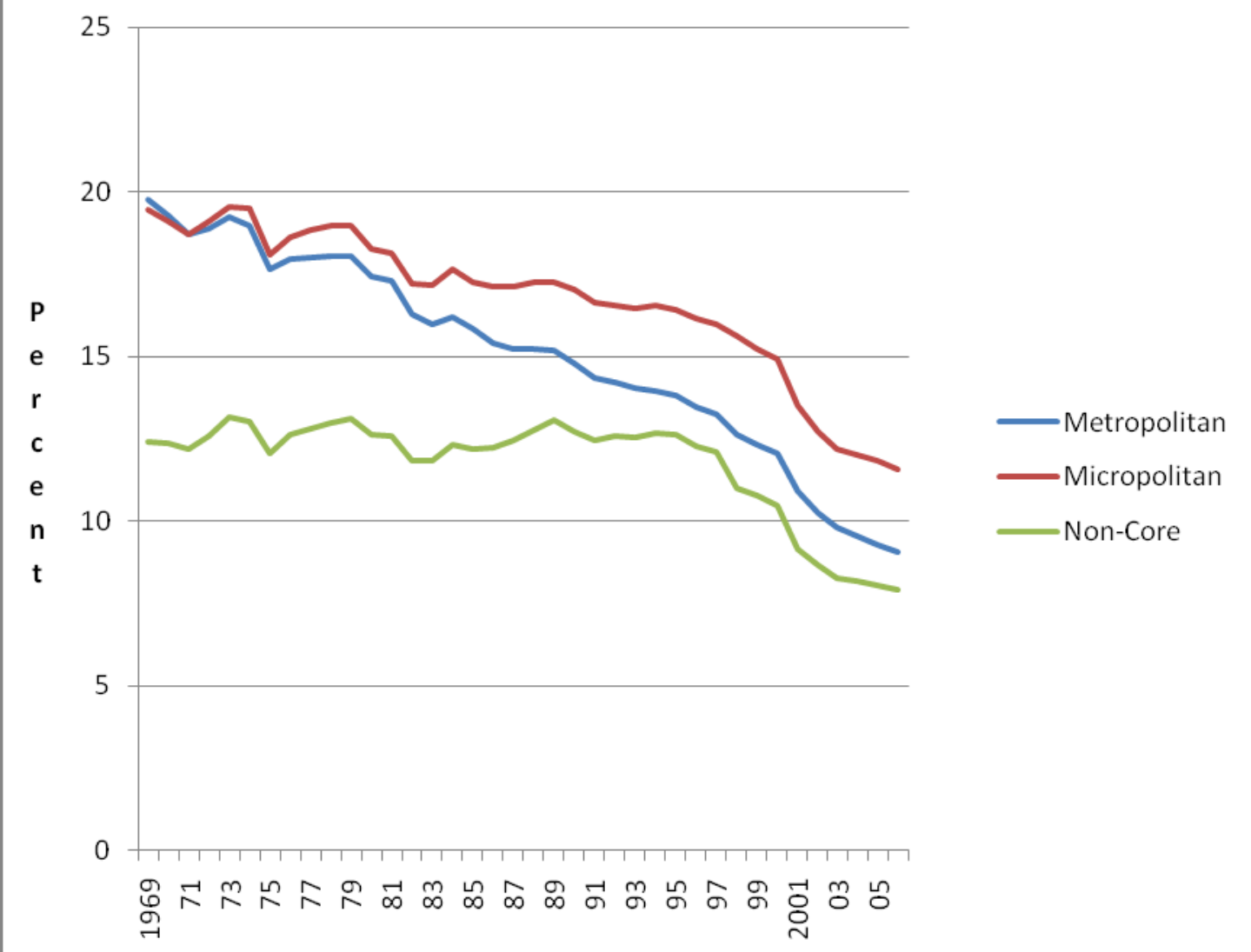




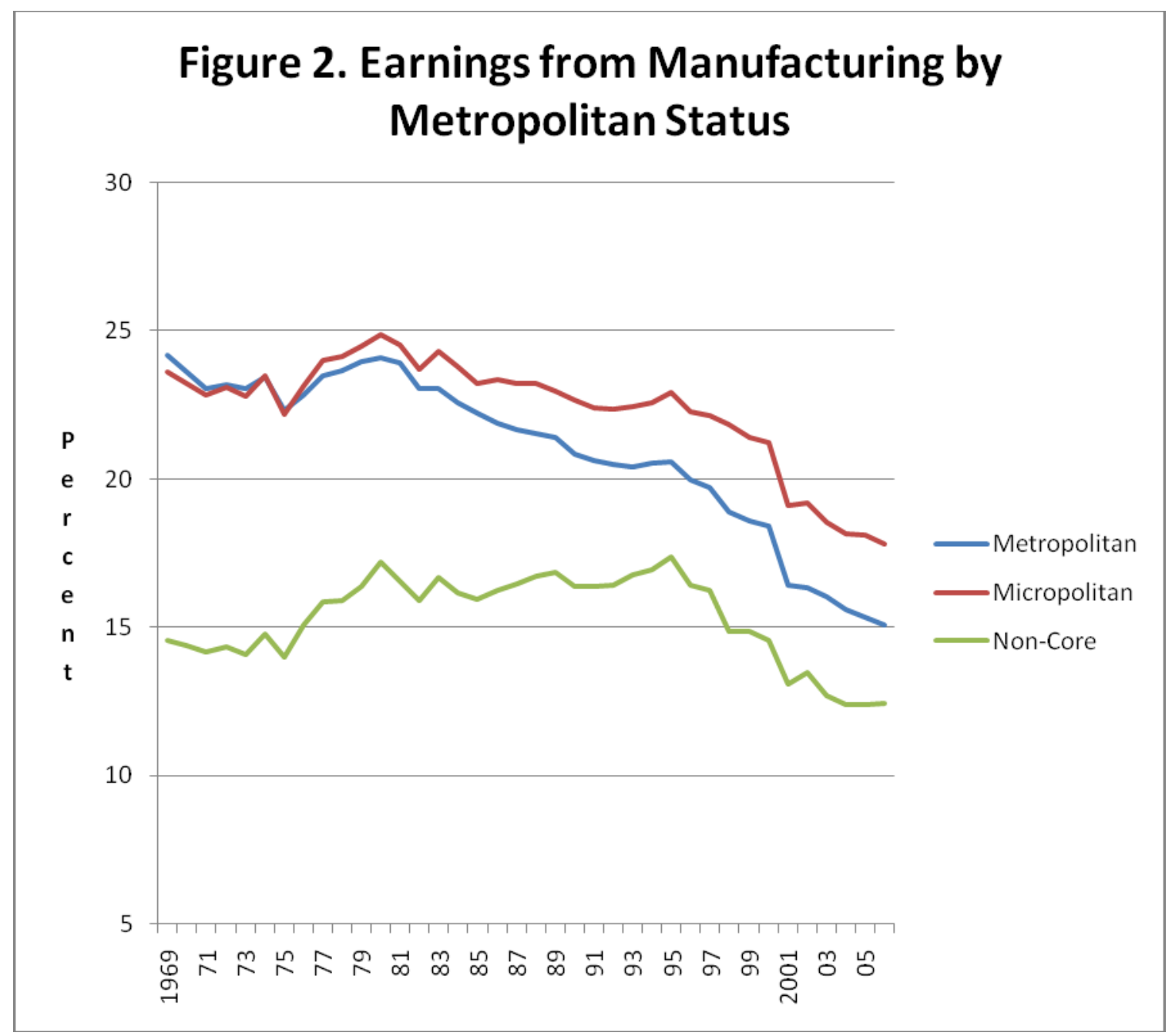




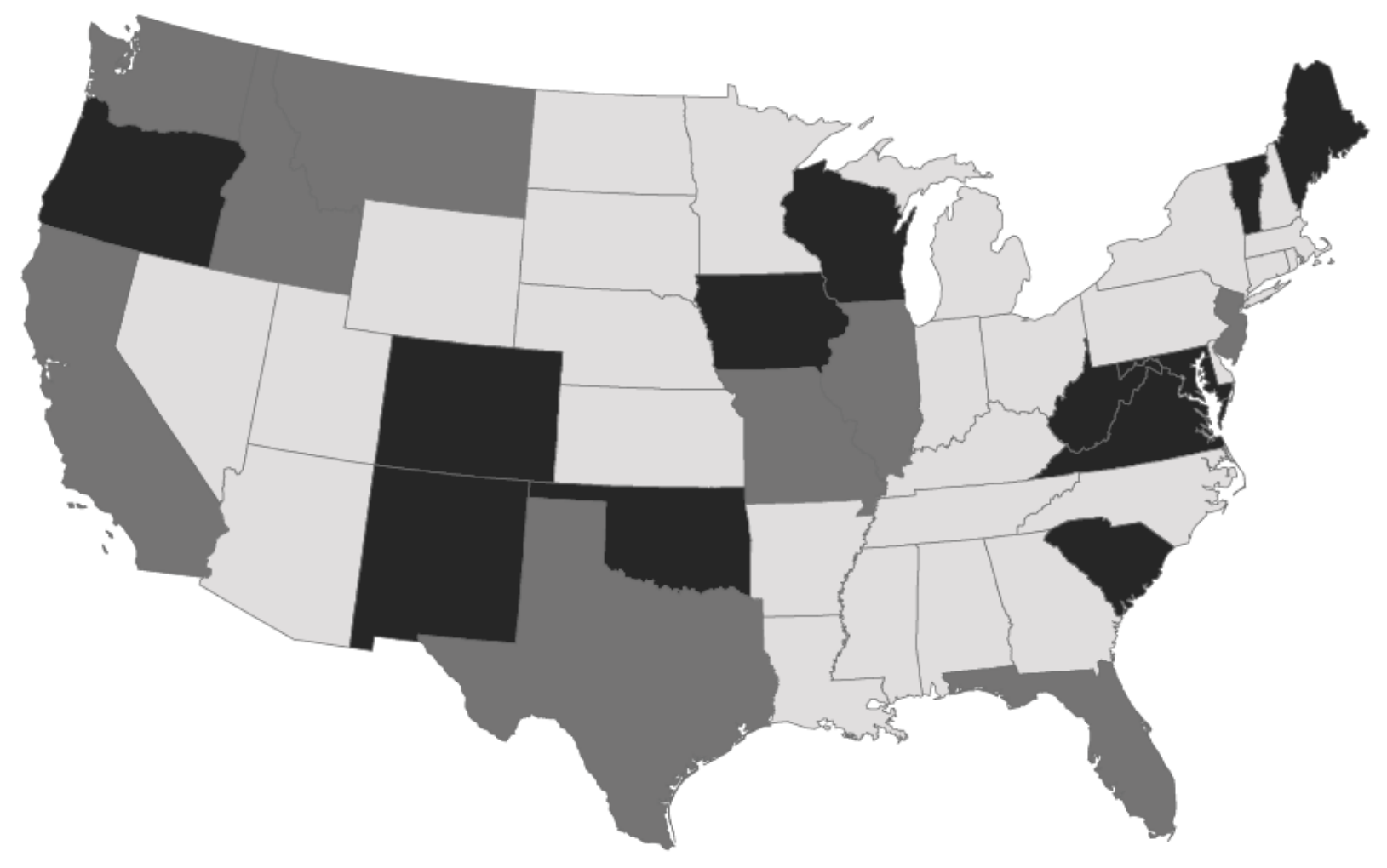

\section{Legend \\ STATES}

Status in Analysis

Not available to include

Available, but not included

Available and included

Figure 3. Status of States in Analysis 
Table 1. Means and Standard Deviations of Individual- and Firm-Level Attributes: Comparisons of Four-Quarter Year 2000 Manufacturing Workers and Jobs Across Micropolitan, and Non-Core Areas

\begin{tabular}{|c|c|c|}
\hline & Micropolitan & Non-Core \\
\hline LN annual earnings of highest paying & 10.35 & 10.22 \\
\hline 4-quarter job in 2000 & $(0.52)^{a}$ & $(0.51)$ \\
\hline Years of experience & 23.42 & 23.28 \\
\hline (derived from age-schooling-6) & (9.89) & $(10.02)$ \\
\hline \multirow[t]{2}{*}{ Years of experience squared } & 646.25 & 642.17 \\
\hline & $(493.52)$ & $(502.46)$ \\
\hline \multirow[t]{2}{*}{ Female worker } & 0.32 & 0.34 \\
\hline & $(0.47)$ & $(0.47)$ \\
\hline \multirow[t]{2}{*}{ Hispanic worker } & 0.04 & 0.02 \\
\hline & $(0.2)$ & $(0.14)$ \\
\hline \multirow[t]{2}{*}{ Black worker } & 0.1 & 0.09 \\
\hline & $(0.3)$ & $(0.29)$ \\
\hline \multirow[t]{2}{*}{ Other race worker } & 0.04 & 0.04 \\
\hline & $(0.2)$ & $(0.18)$ \\
\hline \multirow[t]{2}{*}{ Years of schooling } & 13.06 & 12.87 \\
\hline & $(2.22)$ & (2.19) \\
\hline \multirow{2}{*}{$\begin{array}{l}\text { Number of 4-quarter jobs held } \\
\text { by worker during } 2000\end{array}$} & 1.02 & 1.02 \\
\hline & $(0.16)$ & $(0.16)$ \\
\hline \multirow{2}{*}{$\begin{array}{l}\text { Tenure with establishment } \\
\text { (number of quarters through 2000) }\end{array}$} & 14.13 & 12.53 \\
\hline & $(11.81)$ & $(9.88)$ \\
\hline \multirow{2}{*}{$\begin{array}{l}\text { Duration of establishment presence } \\
\text { in community (quarters through 2000) }\end{array}$} & 25.92 & 25.61 \\
\hline & (16.06) & (15) \\
\hline \multirow{2}{*}{$\begin{array}{l}\text { Single establishment (not part of } \\
\text { multi-establishment enterprise) }\end{array}$} & 0.84 & 0.87 \\
\hline & $(0.37)$ & $(0.33)$ \\
\hline \multirow{2}{*}{$\begin{array}{l}\text { LN establishment size as measured } \\
\text { by number of workers, March, } 2000\end{array}$} & 5.97 & 5.67 \\
\hline & $(1.68)$ & $(1.58)$ \\
\hline
\end{tabular}

${ }^{a}$ Standard deviations in parentheses 
Table 2. OLS Estimates of Individual- and Firm-Level Effects on LN 2000 Annual Earnings: Comparisons of Four-Quarter Manufacturing Workers Across Micropolitan, and Non-Core Areas

\begin{tabular}{|c|c|c|c|c|}
\hline & \multicolumn{2}{|c|}{ Micropolitan } & \multicolumn{2}{|c|}{ Non-Core } \\
\hline & 1 & 2 & 3 & 4 \\
\hline \multirow[t]{2}{*}{ Intercept } & $9.3360 *$ & $9.2612^{*}$ & $9.2437^{*}$ & $9.3070^{*}$ \\
\hline & $(0.0121)^{a}$ & $(0.0134)$ & (0.0153) & $(0.0164)$ \\
\hline \multirow{3}{*}{$\begin{array}{l}\text { Years of experience } \\
\text { (derived from age-schooling-6) }\end{array}$} & $0.0219 *$ & $0.0219 *$ & $0.0222 *$ & $0.0221^{*}$ \\
\hline & $(0.0004)$ & $(0.0004)$ & $(0.0004)$ & $(0.0004)$ \\
\hline & {$[0.4187]^{b}$} & [0.4186] & {$[0.4323]$} & [0.4322] \\
\hline \multirow[t]{3}{*}{ Years of experience squared } & $-0.0004^{*}$ & $-0.0004^{*}$ & $-0.0004 *$ & $-0.0004^{*}$ \\
\hline & $(0.0000)$ & $(0.0000)$ & $(0.0000)$ & $(0.0000)$ \\
\hline & {$[-0.3511]$} & {$[-0.3513]$} & {$[-0.3728]$} & {$[-0.3727]$} \\
\hline \multirow[t]{3}{*}{ Female worker } & $-0.3804^{*}$ & $-0.3806^{*}$ & $-0.3873^{*}$ & $-0.3869 *$ \\
\hline & $(0.0019)$ & $(0.0019)$ & $(0.0021)$ & $(0.0021)$ \\
\hline & {$[-0.3434]$} & {$[-0.3436]$} & {$[-0.3579]$} & {$[-0.3575]$} \\
\hline \multirow[t]{3}{*}{ Hispanic worker } & $-0.3152 *$ & $-0.3152 *$ & $-0.2400 *$ & $-0.2398 *$ \\
\hline & $(0.0046)$ & $(0.0046)$ & $(0.0073)$ & $(0.0073)$ \\
\hline & {$[-0.1187]$} & {$[-0.1187]$} & {$[-0.0637]$} & {$[-0.0636]$} \\
\hline \multirow[t]{3}{*}{ Black worker } & $-0.2400 *$ & $-0.2401^{*}$ & $-0.2546 *$ & $-0.2555^{*}$ \\
\hline & $(0.0033)$ & $(0.0033)$ & (0.0039) & $(0.0039)$ \\
\hline & {$[-0.1405]$} & {$[-0.1406]$} & {$[-0.1440]$} & {$[-0.1444]$} \\
\hline \multirow[t]{3}{*}{ Other race worker } & $-0.0355^{*}$ & $-0.0354^{*}$ & $-0.0357^{*}$ & $-0.0359 *$ \\
\hline & $(0.0044)$ & $(0.0044)$ & $(0.0053)$ & $(0.0053)$ \\
\hline & {$[-0.0137]$} & {$[-0.0136]$} & {$[-0.0128]$} & {$[-0.0129]$} \\
\hline \multirow[t]{3}{*}{ Years of schooling } & $0.0410 *$ & $0.0409 *$ & $0.0419 *$ & $0.0419 *$ \\
\hline & $(0.0004)$ & $(0.0004)$ & $(0.0005)$ & $(0.0005)$ \\
\hline & [0.1758] & [0.1755] & {$[0.1786]$} & [0.1786] \\
\hline \multirow{3}{*}{$\begin{array}{l}\text { Number of 4-quarter jobs held } \\
\text { by worker during } 2000\end{array}$} & $-0.0853^{*}$ & $-0.0852^{*}$ & $-0.0572 *$ & $-0.0572 *$ \\
\hline & $(0.0056)$ & $(0.0056)$ & $(0.0062)$ & $(0.0062)$ \\
\hline & {$[-0.0256]$} & {$[-0.0256]$} & {$[-0.0174]$} & {$[-0.0174]$} \\
\hline \multirow{3}{*}{$\begin{array}{l}\text { Tenure with establishment as } \\
\text { measured by number of quarters } \\
\text { through } 2000\end{array}$} & $0.0073^{*}$ & $0.0160 *$ & $0.0091^{*}$ & $0.0013^{*}$ \\
\hline & $(0.0001)$ & (0.0007) & $(0.0001)$ & $(0.0007)$ \\
\hline & [0.1672] & [0.3639] & [0.1751] & [0.0258] \\
\hline \multirow{3}{*}{$\begin{array}{l}\text { LN establishment size as measured } \\
\text { by number of workers, March, } 2000\end{array}$} & $0.0635^{*}$ & $0.0634^{*}$ & $0.0693^{*}$ & $0.0689 *$ \\
\hline & $(0.0006)$ & $(0.0006)$ & $(0.0006)$ & $(0.0006)$ \\
\hline & [0.2064] & [0.2063] & [0.2137] & [0.2123] \\
\hline \multirow{3}{*}{$\begin{array}{l}\text { Duration of establishment presence } \\
\text { in community as measured in } \\
\text { quarters through end of } 2000\end{array}$} & $-0.0020 *$ & $-0.0020 *$ & $-0.0027^{*}$ & $-0.0026^{*}$ \\
\hline & $(0.0001)$ & $(0.0001)$ & $(0.0001)$ & $(0.0001)$ \\
\hline & {$[-0.0616]$} & {$[-0.0622]$} & {$[-0.0795]$} & {$[-0.0762]$} \\
\hline \multirow{3}{*}{$\begin{array}{l}\text { Single establishment (not part of } \\
\text { multi-establishment enterprise) }\end{array}$} & $-0.0367^{*}$ & $0.0421 *$ & $-0.1042 *$ & $-0.1730^{*}$ \\
\hline & $(0.0038)$ & (0.0070) & $(0.0053)$ & $(0.0082)$ \\
\hline & {$[-0.0259]$} & {$[0.0297]$} & {$[-0.0677]$} & {$[-0.1124]$} \\
\hline \multirow{3}{*}{$\begin{array}{l}\text { Interaction of tenure with establish- } \\
\text { ment and single establishment }\end{array}$} & --- & $-0.0088^{*}$ & --- & $0.0079 *$ \\
\hline & & $(0.0007)$ & & $(0.0007)$ \\
\hline & & {$[-0.2160]$} & & [0.1638] \\
\hline Adjusted R-Square $\times 100$ & 27.50 & 27.55 & 27.43 & 27.47 \\
\hline
\end{tabular}

$* p<0.0001$ 